\title{
An Analysis of Trump's 2016 Campaign Speeches from the Perspective of Social Force in Force-dynamics Theory
}

\author{
Yunyou Wang \\ Department of International Studies, Southwest University, Chongqing, China
}

\begin{abstract}
Using Donald Trump's presidential campaign speeches from 2016 as its corpus, this paper takes Talmy's (1988) force-dynamics theory as a framework for deconstructing and analyzing political discourse from a cognitive perspective. In view of Newton's second law of classical mechanics, this study analyzes the source and composition of social force within force-dynamics theory and constructs a cognitive model of discourse: $\mathbf{F}$ (social force) $=\mathbf{m}$ (quantification of discourse information) * a (discourse strategy), applicable to analysis of the relations among language, rights, and ideology in political discourse. In Trump's campaign speeches, the quantification of discourse information and strategies using cognitive mechanisms such as metaphor, metonymy, and categorization greatly strengthens the social force of the discourse. This plays an important role in conveying Trump's intention to voters, influencing the public's emotions and winning their support-thus changing the original psychological state of voters and finally even influencing the election result.
\end{abstract}

Index Terms-presidential campaign speeches, force-dynamics theory, Newton's second law of classical mechanics, quantification of discourse information, discourse strategy

\section{INTRODUCTION}

The study of political discourse originated in Aristotle's Politics and is interdisciplinary, typically a combination of psychology and anthropology. The study of political discourse from the perspective of linguistics dates to the 1980s, and combines the methodology of critical discourse analysis (CDA) focusing on the relations among language, ideology, and rights with systematic functional grammar. By analyzing specific lexical and grammatical structures, we can deconstruct the ideology behind discourse and explain how participants in political activities achieve an ideological function through speech. In the 1990s, scholars specializing in CDA represented by Van Dijk (1998) studied the relationship between discourse and society from the perspective of social cognition. Van Dijk proposed the "socio-cognitive approach," which emphasizes the fundamental mediating function of the mind between discourse and society. This methodology pays special attention to the central role of the mental model, a context model and knowledge device, in describing the relationships among language, power, and ideology. Van Dijk (2003, 2006a, 2006b) described persuasive political discourse as the discourse activity of developing a mental model in the audience's mind, whereby that the speaker's expression of attitude is an ideological process. Expression of attitude is thus not related only to the speaker's internal mental state, but also to the speaker's ability to manipulate and control an audience.

More recently, cognitive linguistics scholars have called for an analysis of political discourse that looks more deeply into the cognitive level in order to identify how a speaker legitimizes ideology by manipulating the conceptual cognition of the audience. As the constitution of discourse, conceptual representation in discourse carries unequal social power relations and demonstrates coherence characteristics similar to those of ideology in discourse. Lakoff introduced the conceptual metaphor, an important kind of conceptual representation, into the study of political discourse. By analyzing political discourse such as political news, political speeches, and political declarations, he identified the political orientation, political ideas, and values behind political metaphors (Lakoff, 2004, 2006a, 2006b, 2008).

The analysis in this paper focuses on force-dynamics methodology, first introduced by Talmy in 1988. The idea is that the notion of force as it exists in the physical world can be applied to discourse to analyze the meaning of language structures. Force-dynamics theory argues that a given two entities in language behavior can be extended metaphorically to abstract cognition in order to explain the relationship between them in social discourse. As a kind of political discourse, presidential campaign speech involves two groups: the speaker and the audience. Force-dynamics theory therefore offers a theoretical basis for analyzing the power relationship between the candidate and the audience. Has the candidate's discourse been effectively conveyed to voters during the speech? How is it delivered? How does this affect voters? This paper explains the relationship between the candidate and the voters via an analysis of the source and composition of social forces per force-dynamics theory, and interprets the sometimes-opaque ideology in these speeches through CDA at the cognitive level.

This paper takes as its corpus candidate Donald Trump's speeches in support of his "Make America great again" presidential campaign in the key swing states of Florida and Ohio (a total of 24,656 words), applying force-dynamics 
theory with the goal of identifying the ideology behind Trump's success in persuading voters and winning key votes.

\section{Force-dynamics Theory and Newton's Second Law of Classical Mechanics}

Talmy (1988) argued that the idea of "force" in the physical world can be extended to the abstract cognitive domain through metaphorical extension to explain semantic categories such as closed-class elements (shown in the form of grammar) and open-class lexical elements (brought into systematic relationships with one another inside a discourse). When "force-dynamics indicators" appear in text, they reflect the speaker's construal of the scene as a force interaction and prompt the audience to conceptualize the scene in the same way, with various ideological consequences. These indicators can be considered part of the inventory of linguistic categories analyzed in CDA (Hart, 2011). Force-dynamics theory entails that there are two entities in language expressions. One is the agonist (Ago), whose circumstance is at issue and who has an intrinsic force tendency. The other is the antagonist (Ant), who produces a force that acts upon the agonist.

Talmy (1988) divided the "force" contained in language expressions into three categories: physical, psychological, and social. Psychological and social forces are derived from physical force through metaphorical extension, with social force specifically an interaction of psychological forces between sentient entities. The Ant acts on the Ago, which causes a change in the psychological state of the Ago. As a political discourse of a persuasive nature, presidential campaign speeches inevitably involve two major entities: the presidential candidate as Ant and the voters as Ago. Talmy's research is limited to the semantic analysis of two entities in a single sentence, but his interpretation of social force opens the possibility of analysis at the discourse level to explain the force contest between two entities existing in that discourse.

So, what is the source of social forces? What is such a force made of? How is the state of one entity changed by the force exerted by another? Extending Talmy's force metaphor, we can answer these questions by applying Newton's second law of classical mechanics: the magnitude of the acceleration of a body is proportional to the applied force, inversely proportional to the mass of the body, and proportional to the inverse of the mass of the body. The classical formula for this law is $\mathrm{F}=\mathrm{m} * \mathrm{a}$. $\mathrm{F}$ is the external force on the object, " $\mathrm{m}$ " the mass of the object, and "a" acceleration. Basically, this formula shows the traditional physics principle that force equals mass times acceleration, and this law of mechanics in physics can also be applied to the analysis of force in language expression. Talmy (2000) argued that "the most meaningful experience people have in the physical world is 'force-dynamics', including the exertion of force, resistance to force, the overcoming of such resistance, barriers to the exertion of force and the removal of such barriers" (p. 291). Under the force-dynamics framework, F refers to the force that the speaker acts on. Then, what do " $m$ " and "a" refers to?

" $\mathrm{m}$ " is the mass of objects in the classical mechanical formula, and in discourse analysis refers relatively intuitively to the quantification of discourse information conveyed by the discourse itself. Neurocognitive linguistics defines the quantification of information as "the relations between input information and the information contained in the internal system" (Cheng, 1999, p.30) - the more new information is added, the greater the quantification of information. The main variable of mass in language is the quantification of information that can be effectively received by the audience through discourse. When transmitting information, a speaker adopts the obvious assumption that the audience has some background knowledge; the speaker then transfers new information that interprets and supplements the audience's existing knowledge. The purpose of communication in general is essentially to transfer unknown content to an audience. The speaker makes assumptions about background knowledge regarding what the audience is familiar with, relates to, or can infer during the communication process. Unknown information must be contextually related to known information, and exists to supplement the known (Deng, 2009). According to Lakoff (2004), the term "frame" is used to describe the knowledge system in the mind and the background reference for discourse comprehension. To understand discourse correctly, the audience must activate the knowledge system represented by the frame they hold (Wen, 2013). The frame helps the audience accept and understand new information, enhancing the quantification of information by the audience. The construction of a frame can therefore increase the quantification of information in discourse, and thus it determines the language force.

"a," of course, stands for acceleration, and is used in discourse analysis to indicate the application of language strategies and their effects on increasing the force of the discourse when the quantification of information (" $\mathrm{m}$ ") conveyed by the discourse is kept still. Successful and clever language strategies play a key role in enhancing political persuasion and audience psychological appeal, enriching the connotation of discourse, enabling the Ago to feel empathy, and realizing the political intention of the Ant to persuade the Ago. The speaker's discourse can be more effectively conveyed to and understood by the audience, thus changing the psychological state of the audience.

As a kind of political discourse, campaign speech aims to persuade voters, and in this process of communication the audience's internal cognitive mechanism plays a key role. By better understanding these cognitive mechanisms, which also serve as useful analytical tools for discourse, the role of language structure in the formation of concepts can be revealed. 
Language plays a crucial role in translating political desire into social action. If one places Trump (the speaker) and voters (the audience) into the force-dynamics framework, they are viewed as antagonist and agonist respectively, as shown in Fig. 1 below:

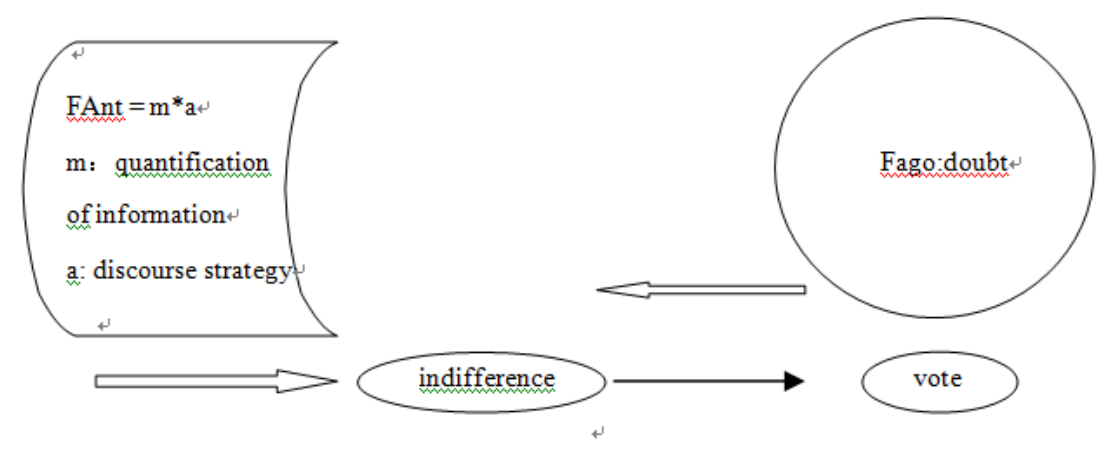

Figure 1

The two opposite arrows in Fig1 represent the two opposing forces, FAnt $(m * a)$ and FAgo. FAnt as $m * a$ means that the force of Trump's words is proportional to the quantification of information (m) modified by the success of his discourse strategy (a). As Barter (1988) notes that utterance is not used to communicate as people often emphasize, but to persuade people. Language is a universal dominant force. Campaign speech is essentially an effort in lobbying voters with its linguistic meaning and features. Translating the " $\mathrm{m}$ " and "a" of the established force-dynamics model into the quantification of information and discourse strategy allows us to conduct a detailed analysis of the two forces involved - Trump's campaign speeches and his audience's beliefs-from the perspective of the cognitive mechanism.

\section{A. " $m$ "-Quantification of Information Conveyed by the Constructed Frame}

Fillmore (1985) defined frames as "specific unified frameworks of knowledge, or "coherent schematization of experience," and proposed frame semantics (p. 222-254). Ungerer and Schmid (2001) added that "frames are just one of a variety of cognitive models which also include the scenarios, domains and interactive networks" (p. 211). On this basis, Lakoff (2004) proposed to apply the concept of frames to the analysis of political discourse, noting that the frame is part of what cognitive scientists call "cognitive unconsciousness"- that is, the cognitive structure in our brain that determines our thinking and judgment, which can be expressed through language (p. xv). All words have a specific conceptual frame that is activated in the brain when we hear them (Lakoff, 2004). Because language is a mirror of society, word frequency can be viewed as a thermometer of sorts for social change. In this paper, the new discourse highlighted in Trump's speeches sets a new frame for his campaign. After a new discourse is successfully brought into a new context by social institutions or actors, it is then transformed into real changes in the physical world in the new social context. Words are thus materialized, triggering social changes we can feel.

In this regard, by analyzing Trump's campaign speeches and applying the keywords research method of corpus linguistics, we can gather the various statistics regarding the keywords appearing in the discourse. The words in the following table all appear more than 10 times, and so are taken to be the keywords in the discourse for the purposes of this analysis. It's easy to notice that in the process of promoting the campaign slogan "Make America great again," Trump focuses on defining keywords - that is, conveying the main connotation through keywords, and sharing common interests and moral points with voters.

TABLE I

\begin{tabular}{|c|c|}
\hline Keyword & Frequency \\
\hline Job & 75 \\
\hline Energy & 20 \\
\hline Tax & 20 \\
\hline Corruption & 17 \\
\hline Poverty & 11 \\
\hline Regulation & 11 \\
\hline
\end{tabular}


In Table 1 we can see that an important component of the campaign slogan "Make America great again" involves the theme of "work." Trump uses this word in his speeches in the swing states 75 times, much more than any other relevant lexical item. This is consistent with his emphasis on the unemployment rate during the Obama administration and efforts to raise voter expectations for a Trump administration. By illustrating the lack of job creation by the current administration, Trump attempts to win voter support. Similarly, elites of the swing states had criticized the tax rate and strict limits on traditional energy sources during Obama's administration, and Trump uses the words "energy" and "tax" 20 times each to win over the votes of the elites and establish the image that the Republican Party would stand up for them. Taken together, the concordance of the three keywords "work," "energy," and "tax" in Trump's remarks construct the "strict father" morality family model that Lakoff argued is typically held by the Republican Party in politics (2004). Lakoff concluded that voters most often do not vote for their own economic interests but for their moral identity and values. That is, people make decisions about politics and candidates based on their value systems, and the language and frames that invoke those values. The Republican Party is adept at using the "strict father" model when promoting its political intentions in order to win the support of voters who hold the same frame (Lakoff, 2004).

The retrieval for the word "job" involves a collection of relevant phrases, such as "bring jobs back," "defend your jobs," and "create jobs." Trump highlights this focus rather succinctly: "My economic agenda can be summed up in three words: jobs, jobs, jobs." The "strict father" model emphasizes what is required for success in the difficult, competitive world. As Lakoff described, "If people are disciplined and pursue their self-interest in this land of opportunity, they will become prosperous and self-reliant. Thus, the strict father model links morality with prosperity" (2004, p.7).

Unlike Clinton, who attached great importance to international cooperation for economic development, Trump's speeches directly highlight the economic issue of increasing domestic employment, and use phrases like "bringing back" and "defend" to establish a frame in which the economic policy adopted by the Obama administration had resulted in high unemployment. In contrast, Trump creates a language environment of employment by establishing employment as the pursuit of interests and independence. This shapes a "strict father" model by creating the moral framework favored by voters.

(1) We are going to bring jobs, opportunity and hope to every community in this nation.

(2) I have a message for all of you tonight: we are going to win Ohio, we are going to win the White House, and we are going to bring back your jobs.

(3) I will renegotiate NAFTA, I will defend your jobs, and I will bring back vehicle production to the United States of America.

When we further examine the retrieval results for the keyword "energy," we find that it largely appears in phrases such as "lifting traditional energy sanctions," "energy reform," and "energy independence." As a major user of traditional energy, the United States was restricted by policies to combat climate change under the Obama administration, which has to some extent weaken the traditional energy sector of United States. The "strict father" model compares the country to a person whose health is reflected in the growth rate of GDP. In the international community, there are nation-adults and nation-children, with maturity metaphorically understood as industrialization. Countries with developed economies are regarded as "nation adults" and independent people (Lakoff, 2004, p. 70). The slogan "Make America great again" is based partly on the recovery of traditional energy industries, and activates the voters' desire to return to economic stability and access a large number of job opportunities when facing economic difficulties. At the same time, energy independence also reflects the values of "independence and power" advocated by Trump and the Republican campaign:

(4) We are going to eliminate regulations that kill American jobs, and that includes getting rid of the Obama administration's anti-energy rules that will raise Ohio's energy bill by more than $40 \%$.

(5) We are going to lift restrictions on all American energy, and we are going to stand up to foreign cheating that threatens steel production in America.

For retrieval of the word "tax," "tax reduction" is the most frequent phrase. This underscores Trump's proposal to use changes in tax rates as a tool to create more jobs and improve standards of living while reducing the cost of production for entrepreneurs. Under the "strict father" Republican frame, it is immoral to give people things they have not earned, because then they will not develop discipline and instead will become dependent (Lakoff, 2004). Per this framework, taxes on social programs are an immoral indulgence of unambitious citizens, while tax reductions are a reward for successful citizens who "obey the rules" and "behave well." Words and phrases such as "lower," "cut," and "bringing down" reflect the "strict father" moral values held by the Republican Party, which gives people more freedom from taxation to pursue economic interests. This kind of morality caters to the need of voters who experienced a slowdown in the U.S. economy and the effects of global economic multi-polarization:

(6) That's why, at the center of my economic plan, is a tax cut for small business-down to 15 percent from 35 percent.

(7) We are going to cut taxes dramatically, and bring thousands of new companies and millions of new jobs to our shores.

(8) A Trump Administration will be a true friend to small business and working Americans. That means bringing 
down taxes, bringing down the price of energy, and bringing down job-killing that cost our economy as much as $\$ 2$ trillion a year.

The contexts of these keywords reflect the core ideas of the slogan "Make America great again" and the language framework it constructs. Presenting himself as a successful businessman, Trump applies the Republican "strict father" framework to attack the Democratic Party's economic policy. At the same time, Trump constructs his own frame and discourse system regarding how to lead the United States to resolve problems in the process of economic development and address vital issues of employment. In doing so, he aligned the interests and morals of his campaign with the aspirations of voters in swing states.

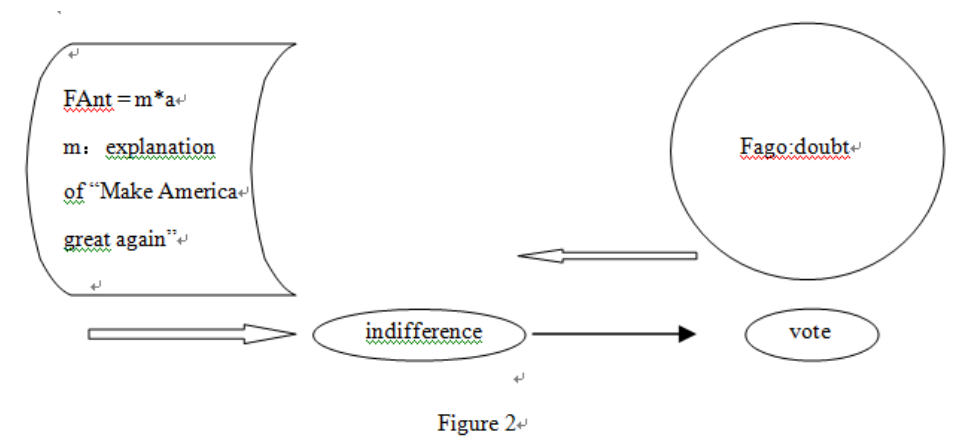

In Fig.2, the opposing large and small arrows represent the two opposing forces of FAnt and FAgo. Per the force-dynamics model, the Ant is Trump's campaign discourse in the swing states, and the Ago is the voters whose support is under contention. By illustrating the content of the slogan "Make America great again," Trump establishes himself as a "strict father" who conforms to the values held by voters, which then increases the amount of "m" (quantification of information) in the discourse and overcomes the intrinsic trend of the Ago, thereby changing the one-sided attitude of some voters towards the image of Trump as a businessman. Diction like "work," "energy," and "tax" illustrates the values underlying the slogan and express the positive attitude that Trump hopes to convey. This approach is intended to give voters a deeper understanding of the substance of "Make America great again," and overcome any initial skepticism resulting from their conventional thinking. This not only increased the support of general and elite classes in Florida and Ohio in the polls, but also laid a solid foundation for Trump's later victory. Americans believed that even if Trump was not the one who prescribed the best medicine for their country, but the one who pointed out its illnesses. Trump's speech is this more down-to-earth compared with Clinton's empty rhetoric.

\section{B. " $a$ "-Representing Discourse Strategies}

We have hundreds of millions of neurons in the brain, each of which can connect to thousands of others, but neurons in one area must be strong enough to activate and send out signals that reach neurons in others. Cognitive mechanisms such as metaphor are essentially a process of connecting neurons in different parts of the brain. Lakoff (2008) argued that people have a "double concept" — that is, two modes of thinking — when dealing with different political issues. This gives rise to "swing voters" who have no fixed neuronal connections to specific political issues. Through the analysis of his campaign speeches in swing states, we can see that to win support from voters Trump uses conceptual representations including metaphor, metonymy, and categorization to strengthen "acceleration" of his language and improve its effectiveness.

1. Metaphor. In cognitive linguistics, metaphor is one of the basic cognitive modes of human beings. It is a conceptual process involving mapping the structure of the source domain to a target domain to describe a relatively complicated and abstract concept in terms of a more familiar and concrete concept (Lakoff \& Johnson, 1980, p. 246-247). Critical metaphor analysis, a combination of metaphor and critical discourse analysis (CDA), is an early and well-developed critical cognitive paradigm. Metaphor uses selective concept mapping, which makes its function of prominence/profile an important tool for the spread of ideology (Charteris, 2004). Metaphor provides a specific empirical frame for political thought and ideology. One purpose is to use social acceptability to legitimize the political interests and propositions of the speaker, and it can also arouse the cognitive and emotional resonance of the discourse audience (Lakoff, 2004).

(9) Hillary Clinton backed her husband's NAFTA, she backed China's entrance into the World Trade Organization, she backed the job-killing trade deal with South Korea, and backed the Trans-Pacific Partnership.

(10) We are going to cancel every needless job-killing regulation, and put a moratorium on new regulations until our economy gets back on its feet.

The word in example (10) "Kill" activates scenes like "life" and "malicious injury, blood and cruelty," which are immoral in themselves. Hillary Clinton's "failed economic policy" is described by Trump as "job-killing," implying that Clinton and her democratic party are the "killers" of the public and that a series of policies proposed by her are the "killer" of American job opportunities. This transfers any of the audience's disappointment or frustration with the 
Obama administration to Hillary Clinton. At the same time, Trump uses the conceptual metaphor of "economic development is a journey" in his speech, and holds that the Trump administration would lead the American economy to "get back on its feet" through the implementation of new policies. Thus, Trump evokes the emotional resonance of voters by using specific images.

2. Metonymy. Metonymy is not only referential, but also conceptual. It involves a cognitive process in which one conceptual entity is mentally accessed via another. The metonymic entity serves as a "reference point" that affords mental access to another conceptual entity, the intended target, and guides the audience to focus on that target (Radden \& Kovecses, 1999). To convey the specific ideology of the discourse, a speaker can apply the cognitive effect of selective prominence or the profile function of metonymy to adjust discourse strategies.

(11) According to Pew Research, immigration over the next fifty years will add another 100 million to our population. It will be much, much more than even that under Hillary Clinton's radical plans. That's unfair to the low-income workers living here today and trying to get ahead.

Through the phrase "add another 100 million," Trump draws the conclusion that this would be "unfair." This involves an internal referential concept transfer process and the "attribute for entity" metonymy. In the given domain of "a group of people," the speaker focuses on a negative attribute, like the suggestion that increased population also increases the difficulty of employment. However, Trump represents immigration as only an increase in population, and attributes unemployment to overpopulation caused by immigrants; the positive impact of immigrants on promoting cultural diversity and improving work efficiency are not mentioned. The process of metonymy in an idealized cognitive model (ICM), which is constructed through experience (including discourse) and applied to explain experiences. People use their knowledge representation of the world in their brains and the cultural patterns in which they live to achieve their cognition of objects, events, and themselves in the objective world. Trump's strategy combines the cognition of "immigrants entering the United States," "low-income Americans," and "declining employment rate" to form a new language frame and achieve the purpose of metaphorical thinking. This approach demonstrates how Trump attaches great importance to attracting the middle and low income groups in swing states during his campaign speeches, and works to gain support by highlighting the demands and dissatisfaction of this group.

3. Categorization. Categorization is a conceptual structure used to divide objects, entity actions, event scenarios, and processes into specific types. In cognitive linguistics, categorization is another ICM, the operation of construal based on comparison. According to Croft and Cruse (2004), “The most fundamental judgment of comparison is categorizations. The act of categorization-applying a word, morpheme or construction to a particular experience to be communicated - involves comparison of the experience in question to prior experiences and judging it to belong to the class of prior experiences to which the linguistic expression has been applied" (p. 54).

(12) My economic agenda can be summed up in three words: jobs, jobs, jobs.

(13) I am asking for your vote so we can create a New American future which includes millions of new jobs through lower taxes, less regulations and trade deals that put America first.

The boundary between categories is fuzzy, and it is relatively easy to produce word-meaning infection. Trump reiterated the goal to "Make America great again," focusing on reducing national regulation, cutting taxes, and boosting employment. Through mentioning the three issues in the same breath, Trump produces a semantic infection that incorporates them into the same category, thus forming and validating Trump's tit-for-tat economic-development ideas. This also demonstrates Trump's most direct reaction to addressing the problem of what he describes as a weak U.S. economy.

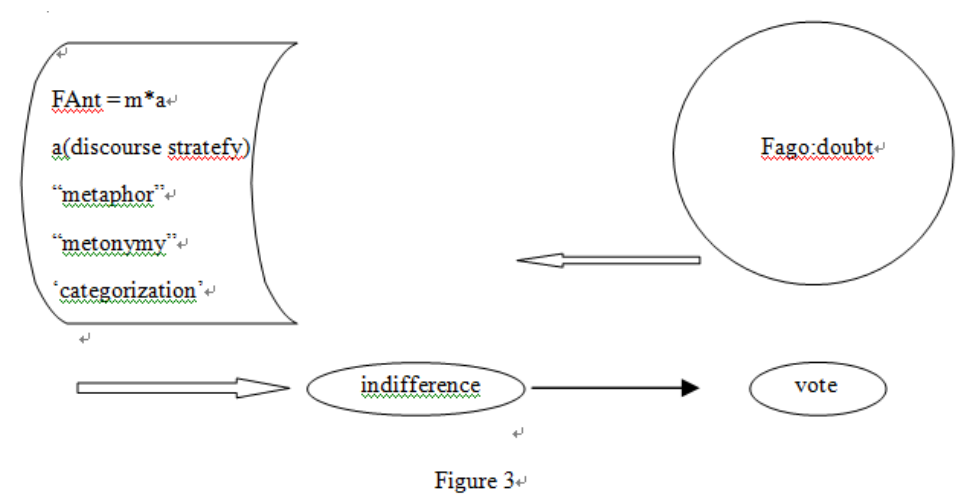

In Fig.3, the two arrows again represent FAnt and FAgo, with the antagonist Trump's campaign speech and the agonist the voters. By analyzing the construal operations of "metaphor," "metonymy," and "categorization" in Trump's speeches, we can see how the voters' cognitive mechanisms have been strengthened in specific ways. The effects of "a" (discourse strategy) have been enhanced, which overcomes the intrinsic trend of the agonist to resist-namely, the voters' attitude regarding Trump's speeches has been changed to be more positive. 


\section{CONCLUSION}

Based on force-dynamics theory, this paper introduces the formula $\mathrm{F}=\mathrm{m} * \mathrm{a}$ from Newton's second law of classical mechanics and constructs a discourse cognitive model wherein $\mathrm{F}$ ( social force) $=\mathrm{m}$ (quantification of information) $* \mathrm{a}$ (discourse strategy). This allows a qualitative and quantitative analysis of how Donald Trump's campaign speeches in 2016 were designed to impact voters in swing states. In Trump's speeches about how to "Make America great again," the force of the FAnt (the force of his speeches) is increased by improving the "m" (quantification of information) and utilizing "a" (discourse strategy) to generate a driving force on the FAgo and urge it to change its intrinsic trend. In other words, by increasing the force of the discourse, Trump attempted to motivate voters in key swing states to change their attitude towards Trump and vote for him.

Perhaps because he had no political background, Trump put considerable emphasis on illustrating the connotations of the campaign slogan "Make America great again." On one hand, he used his own language system and the Republican Party's "strict father" frame to cater to voters' expectation for a more powerful and stronger government when facing the intricacies of global economics and politics. On the other, Trump conveyed the message to voters that he was capable of dealing with severe economic issues, and in particular of improving job opportunities at home, reviving traditional industries, and consolidating the government's relations with large American business groups. This signaled to voters that he can deliver on feasible economic reforms. Additionally, he targeted voters of different party affiliation, race, and gender by making the Republican Party's partisan political policies more universal. This required Trump to make full use of discourse strategies, to hold a more equal and friendly attitude regarding the national public, to convey the commitment of the campaign slogan "Make America great again," and to avoid struggling with the Democratic Party on issues such as international status and environmental protection. To achieve this, Trump speeches focused on the quantification of information within the frame and on discourse strategies. The force-dynamics discourse analysis model constructed here helps us to better understand the role of the Trump administration in shaping national identity and conveying national will both at home and abroad, and lays a solid foundation for the analysis of Trump's policies after he took office.

\section{REFERENCES}

[1] Barthes, R. (1964). Éléments de sémiologie, Communications 4. Paris: Seuil.

[2] Cheng, Q. L. (1999). Introduction to neurocognitive linguistics. Beijing: Foreign Language Teaching and Research Press.

[3] Charteris-Black J. (2004). Corpus approach to critical metaphprs analysis. NY: Palgrave Macmillian.

[4] Croft, W. \& Cruse, D. A. (2004). Cognitive linguistics. Cambridge: Cambridge University Press.

[5] Deng, J. (2009). A Cognitive study on discourse information processing. Foreign Languages and Their Teaching, 3, 4-8.

[6] Fillmore, C. (1985). Frames and the semantics of understanding. Quaderni di Semantica, 6(2), 222-254.

[7] Hart, C. (2011). Force-interactive patterns in immigration discourse: A cognitive linguistic approach to CDA. Discourse \& Society, 3, 269-286.

[8] Lakoff, G. (2004). Don't think of an elephant! Know your values and frame the debate. Hartford, CT: Chelsea Green Publishin

[9] Lakoff, G. (2006a). Whose freedom: The battle over America's most important idea. New York, NY: Farrar, Straus and Giroux.

[10] Lakoff, G. (2006b). Thinking points: Communicating our American values and vision. New York, NY: Farrar, Straus and Giroux.

[11] Lakoff, G. (2008). The political mind: Why you can't understand $21^{\text {st }}$ century politics with an 18 th century brain. New York, NY: Viking.

[12] Lakoff, G. \& Johnson, M. (1980). Metaphors we live by. Chicago, IL: University of Chicago Press.

[13] Radden, G. \& Kovecse, Z. S. (1999). Towards a theory of metonymy. In K. Panther \& G. Radden (Eds.), Metonymy in language and thought. Amsterdam: John Benjamins Publishing Co.

[14] Talmy, L. (1988). Force dynamics in language and cognition, Cognitive Science, 12, 49-100.

[15] Talmy, L. (2000). Toward a cognitive semantics (language, speech, and communication): Concept structuring systems (Volume 1).Cambridge: MIT Press.

[16] Ungerer, F. \& Schmid, H. J. (2001). An introduction to cognitive linguistics. Beijing: Foreign Language Teaching and Research Press.

[17] Van Dijk, T. (1998). Ideology: A multidisciplinary approach. London: Sage.

[18] Van Dijk, T. (2003). Knowledge in parliamentary debates. Journal of Language and Politics, 2(1), 93-129.

[19] Van Dijk, T. (2006a). Discourse and manipulation. Discourse \& Society, 17, 359-383.

[20] Van Dijk, T. (2006b). Discourse, Context and Cognition. Discourse Studies, 8(1), 159-177.

[21] Wen, X. (2013). Frame and utterance interpretation. Foreign Studies, 1(1), 27-33, 99.

Yunyou Wang, born on $1^{\text {st }}$, December, 1991, is studying in Southwest University of China as a PHD candidate, majoring in English Language and linguistics, and focusing on the research of cognitive linguistics. In 2013, she graduated from the University of Electronic Science and Technology of China (UESTC) as an English major with a bachelor's degree and then got the master's degree of interpreting and translation in Chongqing University in 2015. Later on, she was working in China Mobile as a secretary for one year, and then successfully enrolled in Southwest University as a PHD candidate. 